\title{
Protective effect of midazolam against convulsion in neonatal rats via down-regulation of LC3 and Beclin-1 expression
}

\author{
Juan Shi ${ }^{1}$, Shuzhong Jiang ${ }^{2}$, Qinhua Wang ${ }^{3}$, Jiajia Hua ${ }^{4}$, Feifan $\mathrm{Xu}^{5}$, Delin $\mathrm{Gu}^{6}$, \\ Hui Zhou ${ }^{7 *}$ \\ ${ }^{1}$ Department of Pediatrics, ${ }^{2}$ Department of Gastroenterology, ${ }^{3}$ Animal Laboratory, ${ }^{4}$ Department of Traditional Chinese Medicine, \\ ${ }^{5}$ Department of Clinical Laboratory, ${ }^{6}$ Science and Education Section, The Sixth People's Hospital of Nantong, ${ }^{7}$ Department of \\ Pediatrics, Affiliated Hospital of Nantong University, Nantong, Jiangsu Province 226011, China
}

*For correspondence: Email: MarcusLaurafBkC@yahoo.com; Tel: 0086-0513-80886688

\begin{abstract}
Purpose: To investigate the effect of midazolam on growth of neurocytes in vitro and in neonatal rats. Methods: Neurocyte proliferation and activity of lactate dehydrogenase were assessed by MTT and lactate dehydrogenase assays, respectively. Western blotting was used to determine the effect of midazolam on LC3, Bax, p62 and Beclin-1 protein expressions.

Results: The suppression of neurocyte proliferation byconvulsion was alleviated significantly $(p<0.05)$ by midazolum treatment. Exposure of convulsion model of neurocytes to midazolum suppressed $L C 3$, Bax, p62 and Beclin-1 protein expression. Midazolum exposure of convulsion model of neurocytes suppressed LDH, caspase-3, caspase-8 and caspase-9 activities. The 3-MA (autophagy inhibitor) treatment also significantly $(p<0.05)$ promoted neurocyte viability after convulsion induction. In convulsion-induced neurocytes, 3-MA exposure suppressed expression of caspase-3/8/9, LC3, Bax, Beclin-1 and p62, while application of midazolum treatment to the rats with convulsion markedly decreased brain water content and neurocyte apoptosis $(p<0.05)$. Treatment with midazolum inhibited LC3, p62 and Beclin-1 expression in the rat model of convulsion.

Conclusion: Midazolum promotes neurocyte proliferation and inhibits edema development via downregulation of autophagy. Therefore, midazolum can potentially be used for the treatment of convulsion, but further studies need to be carried out first.
\end{abstract}

Keywords: Convulsion, Neurocytes, Caspase, Autophagy, Mitochondrial pathway

\begin{abstract}
This is an Open Access article that uses a fund-ing model which does not charge readers or their institutions for access and distributed under the terms of the Creative Commons Attribution License (http://creativecommons.org/licenses/by/4.0) and the Budapest Open Access Initiative (http://www.budapestopenaccessinitiative.org/read), which permit unrestricted use, distribution, and reproduction in any medium, provided the original work is properly credited.

Tropical Journal of Pharmaceutical Research is indexed by Science Citation Index (SciSearch), Scopus, International Pharmaceutical Abstract, Chemical Abstracts, Embase, Index Copernicus, EBSCO, African Index Medicus, JournalSeek, Journal Citation Reports/Science Edition, Directory of Open Access Journals (DOAJ), African Journal Online, Bioline International, Open-J-Gate and Pharmacy Abstracts
\end{abstract}

\section{INTRODUCTION}

Recurrent convulsion is a neurological disorder that endangers the lives of children at different stages of development and hinders their growth physically as well as intellectually [1]. Convulsion is responsible for psychological, cognitive and behavioral abnormalities in children which usually persist at adult stage [2,3]. Recurrent convulsion leads to economic as well as psychological burden on the families of patients and country as a whole [2,3]. Generally, 
convulsion in patients is persistent and recurrent [3]. The major damage to brain during recurrent convulsion is caused by the activation of apoptotic pathway [4]. Apoptosis induction during central nervous disorders has been found to involve mitochondrial pathway [5]. Downregulation of mitochondrial pathway is therefore believed to be of prime importance to explore the role of therapeutic agents in the treatment of convulsion [5]. The two main methods of cell death in multi-cellular organisms are necrosis and apoptosis [6]. The organelle damage and excessive environmental pressure leads to necrosis which is an abnormal and passive method of cell death [5]. The genetically regulated process for maintaining homeostasis and eliminating cells from the body is apoptosis [5]. The third method of cell death in which degradation of organelles and proteins by lysosomes takes place is known as autophagy [5]. During neurological damage, autophagy activates apoptosis-promoting factors leading to apoptotic cell death [7].

Midazolam is a member of benzodiazepine class which is used as anesthesia for inducing sedation. It is a receptor agonist for various members of class benzodiazepine and has been found to induce no harmful effect on development of neurons [8]. During anesthesia midazolam plays an important role in protecting the dendrites [8]. Midazolam exposure of hematologia, ectoderm and mesenchymal carcinoma cells has been found to activate cell apoptosis [9-11]. Midazolam is known for its potential as agonist for peripherally-distributed benzodiazepine receptors $[12,13]$. The peripherally distributed benzodiazepine receptors play vital role in the cellular processes like proliferation and growth [12,13]. The present study investigated the effect of midazolum on growth and proliferation of neurocyte cells of convulsion model in vitro and in vivo.

\section{EXPERIMENTAL}

\section{Neonatal rats}

A total of 40 neonatal rats (Wistar strain, 6-12 g) were supplied by the Second Affiliated Hospital of Xi'an, Jiaotong University, China. The neonatal rats were given free access to water and feed. All the rats were maintained under 12$\mathrm{h}$ light/12-hdark cycles at $23^{\circ} \mathrm{C}$ and $65 \%$ humidity. The animal experimental procedures were conducted as per the National Institute of Health guidelines [14] and approval was obtained from Ethics Committee, Nantong University, Nantong China (approval no. 2014/2Tx1221). The decapitation method was used for sacrificing the rats after anaesthetization using mixture of xylazine $(10 \mathrm{mg} / \mathrm{kg})$ and ketamine hydrochloride $(80 \mathrm{mg} / \mathrm{kg})$ through intraperitoneal route.

\section{Preparation of SC model rats}

The convulsion model of neonatal rats was prepared by administration of $\mathrm{LiCl}$-pilocarpine mixture as reported earlier [15]. Pilocarpine (30 $\mathrm{mg} / \mathrm{kg}$ ) was intraperitoneally injected to the rats after $20 \mathrm{~h}$ of $\mathrm{LiCl}(127 \mathrm{mg} / \mathrm{kg})$ administration to induce convulsion. The treatment group was given $5 \mathrm{mg} / \mathrm{kg}$ dose of midazolum intraperitoneally $10 \mathrm{~min}$ after convulsion induction. The rats in control group received $\mathrm{LiCl}$ and chloral hydrate but not pilocarpine.

\section{Study design}

Forty neonatal rats were assigned to control, untreated convulsion, midazolum treatment and 3-MA administration groups. The rats were sacrificed $24 \mathrm{~h}$ after convulsion induction following anaesthetization with xylazine (10 $\mathrm{mg} / \mathrm{kg}$ ) and ketamine hydrochloride $(80 \mathrm{mg} / \mathrm{kg}$ ) mixture. The brain tissues were excised for examination of edema formation and analysis of neurocyte growth using hematoxylin and eosin staining. The expression of proteins in brain tissues was assayed by western blot assay.

\section{Measurement of water content of brain}

The rats after $24 \mathrm{~h}$ of convulsion induction were sacrificed to excise the brain tissues which were subsequently washed two times with PBS. The brain samples were weighed to record the wet weight and then dried at $70{ }^{\circ} \mathrm{C}$ to measure the dry weight. The brain edema was measured by determining the difference between the wet and dry weights.

\section{Hematoxylin and eosin (H\&E) staining}

The neurocyte growth was examined after hippocampus tissues were stained with Haematoxylin and eosin (H\&E). The hippocampus tissues excised from the neonatal rats were subjected to fixing for $24 \mathrm{~h}$ with paraformaldehyde (4\%). The tissues after paraffin-embedding were cut into $3 \mu \mathrm{m}$ slices and then stained for $10 \mathrm{~min}$ with $\mathrm{H} \& \mathrm{E}$ at room temperature. The confocal microscope was used for histopathological examination of the tissue sections.

\section{Culture of neuro-2A}

Neurocyte cells were obtained from the Chinese Academy of Sciences (Shanghai, China). 
Dulbecco's modified Eagle's medium mixed with fetal bovine serum (10\%; FBS) was used for the cell culture. The medium also contained antibiotics such as penicillin $(100 \mathrm{U} / \mathrm{ml})$ and streptomycin $(100 \mu \mathrm{g} / \mathrm{ml})$. The cell cultures were performed in incubator containing $5 \% \mathrm{CO}_{2}$ at $37^{\circ} \mathrm{C}$. The cells were stimulated with xylazine and ketamine hydrochloride mixture for inducing convulsion. The neurocytes were incubated with $5 \mu \mathrm{M}$ solution of $3-\mathrm{MA}$ prior to xylazine and ketamine hydrochloride treatment.

\section{Cell viability assay}

Neurocyte cell viability was measured by(3-(4,5dimethylthiazol-2-yl)-2,5-diphenyltetrazolium bromide) (MTT) proliferation assay. The neurocytes stimulated with xylazine and ketamine hydrochloride for convulsion were exposed to $5 \mu \mathrm{M}$ of midazolam for $12,24,48$ and $72 \mathrm{~h}$ in 96 -well plates. Then, $5 \mathrm{mg} / \mathrm{mL}$ MTT solution $(20 \mu \mathrm{L})$ was added to the plates, and incubation for $2 \mathrm{~h}$ was continued. The medium was completely aspirated from the plates and $120 \mu \mathrm{L}$ dimethyl sulfoxide was added. Cell viability was determined by measuring absorbance of plates using microplate reader at $568 \mathrm{~nm}$.

\section{Analysis of lactate dehydrogenase activity}

The activity of LDH in neurocytes after xylazine and ketamine hydrochloride stimulation and subsequent exposure to $5 \mu \mathrm{M}$ midazolam was determined using LDH Detection kit. The absorbance measurements were made at 445 $\mathrm{nm}$ using microplate reader for determination of LDH activity.

\section{Determination of caspase-3, caspase-8 and caspase- 9 activity}

The neurocytes after xylazine and ketamine hydrochloride stimulation and subsequent exposure to $5 \mu \mathrm{M}$ midazolam were lysed on treatment with RIPA buffer at $4^{\circ} \mathrm{C}$. Centrifugation of the lysate for $20 \mathrm{~min}$ at $3,000 \times \mathrm{g}$ at $4^{\circ} \mathrm{C}$ was followed by BCA assay. The proteins were resolved by electrophoresis on $10 \%$ SDS polyacrylamide gel and subsequently transferred to PVDF membrane. Incubation of membranes was carried out with primary antibodies against caspase-3, caspase-8 and caspase-9. The enzyme Immuno analyzers were used to measure optical density at $402 \mathrm{~nm}$.

\section{Western blot analysis}

Homogenization of brain tissues or lysis of neurocytes was performed on treatment with
RIPA buffer for $25 \mathrm{~min}$ at $4^{\circ} \mathrm{C}$. Centrifugation of the lysate for $15 \mathrm{~min}$ at $3,500 \times \mathrm{g}$ at $4{ }^{\circ} \mathrm{C}$ was followed by measurement of protein content by BCA method. Protein $(20 \mu g)$ samples were loaded on $10 \%$ SDS-PAGE for separation by electrophoresis. The proteins were subsequently transferred to PVDF membrane in which nonspecific sites were blocked on incubation for $1 \mathrm{~h}$ with $5 \%$ non-fat milk in TBST. Incubation of membranes was performed against primary antibodies against Bax, Beclin-1, p62, LC3 and GAPDH (all from Cell Signaling Technology, Inc., Danvers, MA, USA). The membrane washing was followed by $1 \mathrm{~h}$ incubation with horseradish peroxidase-labeled goat anti-rabbit IgG secondary antibody at room temperature. The enhanced chemiluminescence kit was used for band visualization.

\section{Statistical analysis}

The data are presented as mean \pm standard deviation. All statistical analyses were performed using SPSS software (version 20.0; IBM Corp, Armonk, NY, USA). Data analysis was carried out using one-way analysis of variance and Tukey's multiple comparison test. The differences were taken statistically significant at $p$ $<0.05$.

\section{RESULTS}

\section{Midazolum treatment increases neurocyte proliferation}

The proliferation rate of convulsion model of neurocytes was significantly $(p<0.05)$ lower than those of normal neurocytes (Figure 1A). Treatment of convulsion model of neurocytes with midazolum significantly $(p<0.05)$ increased the proliferation rate. The proliferation rate of convulsion model of neurocytes showed a significant $(p<0.05)$ increase on treatment with midazolum for $72 \mathrm{~h}$ (Figure 1B).

\section{Midazolum treatment of neurocytes inhibited autophagy in vitro}

The levels of LC3-2 and Beclin-1 were markedly higher in neurocytes of in vitro convulsion model (Figure 2). In convulsion model of neurocytes, Bax and p62 expression were much higher than those of control neurocytes. Exposure of convulsion model of neurocytes to midazolum suppressed expression of LC3-2 and Beclin-1 when compared to negative control. Midazolum treatment markedly suppressed the levels of Bax and p62 in convulsion model of neurocytes. 


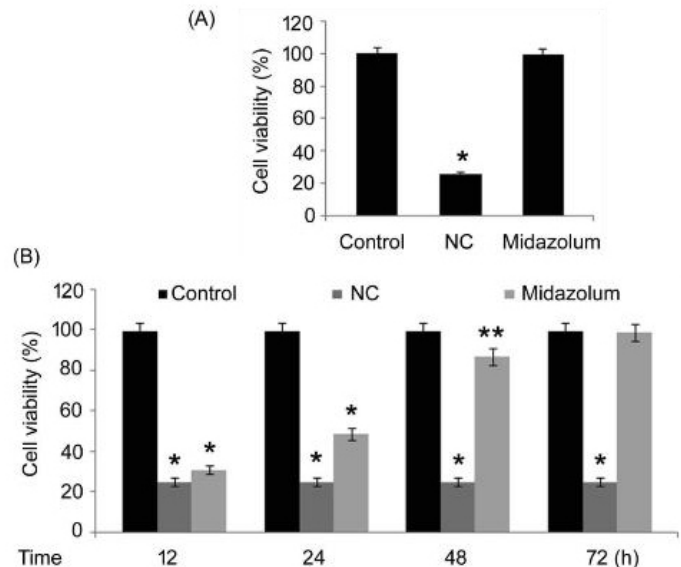

Figure 1: Effect of midazolum on neurocyte viability. (A) The viability of convulsion model of neurocytes was measured after $72 \mathrm{~h}$ exposure to midazolum (5 $\mu \mathrm{M})$. (B) The convulsion model of neurocytes was exposed to midazolum for $12,24,48$ and $72 \mathrm{~h}$ and changes in viability were measured by MTT assay; ${ }^{*} p$ $<0.02$ and ${ }^{* *} p<.01$ vs. negative control neurocytes

(B)
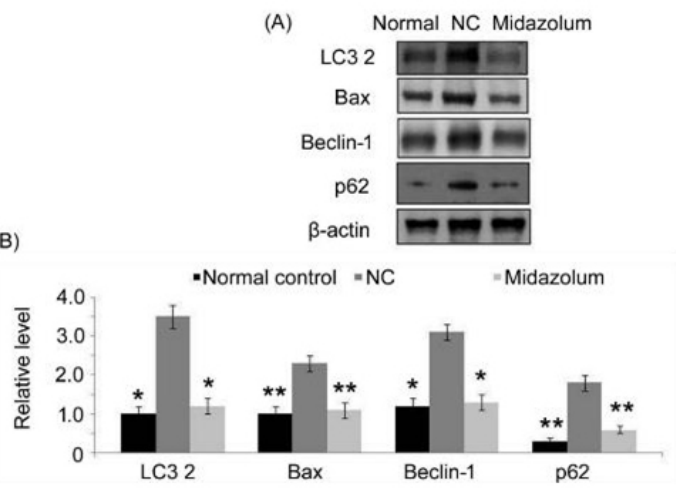

Figure 2: Midazolum changes expression of autophagy related factors in vitro in neurocytes. (A) Exposure of neurocytes in vitro to midazolum was followed by western blotting for assessment of LC3-2, Bax, Beclin-1 and p62 expression. (B) The expression was quantified using $\beta$-actin as internal control; ${ }^{*} p<$ 0.02 and ${ }^{* *} p<0.01$ vs. negative control neurocytes

Midazolum treatment suppressed LDH activity, and caspase-3, caspase-8 and caspase-9 levels in neurocytes in vitro

The activity of LDH in convulsion model of neurocytes was markedly higher compared to the normal neurocytes (Figure 3). Midazolum exposure of convulsion model of neurocytes suppressed the activity of LDH. The caspase-3, caspase-8 and caspase-9levels were also higher in convulsion model of neurocytes in vitro compared to the normal cells. Exposure of convulsion model of neurocyte cells to midazolum decreased the levels of caspase-3, caspase-8 and caspase-9.
(A)

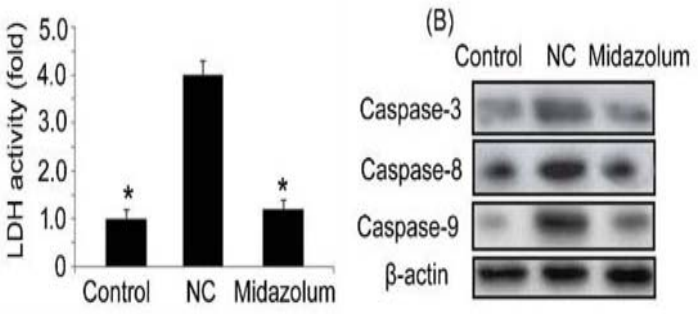

Figure 3: Effect of midazolum on LDH activity and caspase-3, caspase-8 and caspase-9activation in convulsion model of neurocytes. The LDH activity and caspase-3, caspase-8 and caspase-9expression in convulsion model of neurocytes was analyzed using ELISA kits. ${ }^{*} p<02$ and ${ }^{* *} p<0.01$ vs. the untreated neurocytes

\section{Effect of autophagy inhibitor on neurocyte viability}

To ascertain whether midazolum promotes proliferation of convulsion model of neurocytes through inhibition of autophagy, neurocytes were exposed to 3-MA before inducing convulsion. Exposure of convulsion model of neurocytes to 3-MA (autophagy inhibitor) significantly promoted convulsion induced reduction of neurocyte viability (Figure 4).

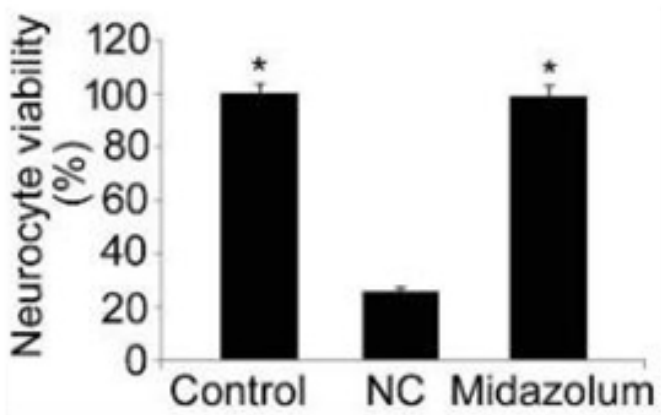

Figure 4: Effect of 3-MA on convulsion induced suppression of neurocyte viability. The convulsion model of neurocyte cells was exposed to 3-MA and viability was determined using MTT assay; ${ }^{*} p<0.02$ vs. untreated neurocytes.

\section{Effect of autophagy inhibitor on caspase- $3 / 8 / 9$ and autophagy inducers in neurocytes}

In convulsion model of neurocytes 3-MA treatment reduced the expression of LC3-2, Bax, Beclin-1 and p62 markedly compared to untreated neurocytes (Figure 5). The 3-MA treatment of convulsion model of neurocytes also caused a marked decrease in LDH activity. 


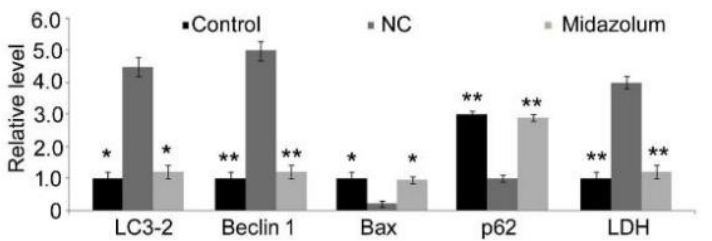

Figure 5: Effect of 3-MA on autophagic factors and LDH activity in neurocytes. (A) The convulsion model of neurocytes was exposed to 3-MA and protein expression was assessed by western blot assay. ELISA kit was used to determine LDH activity. ${ }^{*} p<$ 0.02 vs untreated neurocytes

\section{Midazolum promote growth of neurocyte cells in rats with convulsion}

The growth of neurocyte cells and water content in the brain of rats with convulsion was assessed following treatment with midazolum (Figure 6). The water content in the brain of rats with convulsion was markedly increased compared to midazolum treatment and normal control groups (Figure 6A). The apoptosis rate of neurocyte cells was significantly $(p<0.05)$ higher in untreated rats with convulsion than in midazolum treatment and normal control rats (Figure 6B). Midazolum treatment of the rats with convulsion decreased brain water content and apoptosis of neurocyte cells.
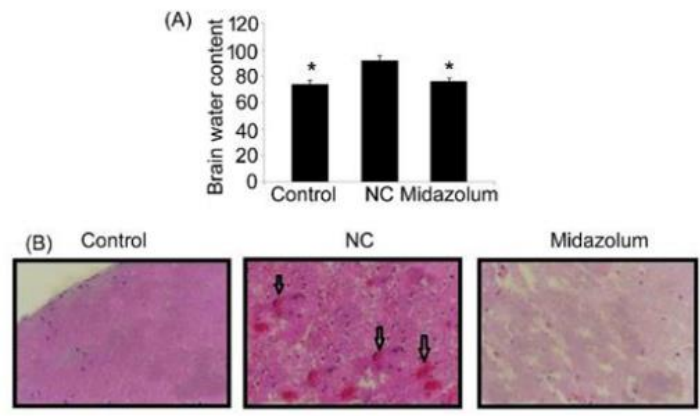

Figure 6: Effect of midazolum on neurocyte cell growth in rat model of convulsion. (A) Hematoxylin \& Eosin stained brain tissue samples were examined for detection of apoptosis (magnification, x100). (B) The content of water in the brain tissues of rats was measured. ${ }^{*} p<0.05,{ }^{* *} p<0.02$ vs. the untreated convulsion rat group

\section{Midazolum reduced Bax and caspase-3/8/9 in rats with convulsion}

The level of Bax in rats with convulsion was markedly higher compared to midazolum treatment and normal control rats (Figure 7). In rats with convulsion the activity of caspase- 3 , caspase-8 and caspase-9was also higher compared to normal control rats. The midazolum treatment of rats with convulsion markedly reduced the activity of caspase- 3 , caspase- 8 and caspase-9 compared to untreated group.

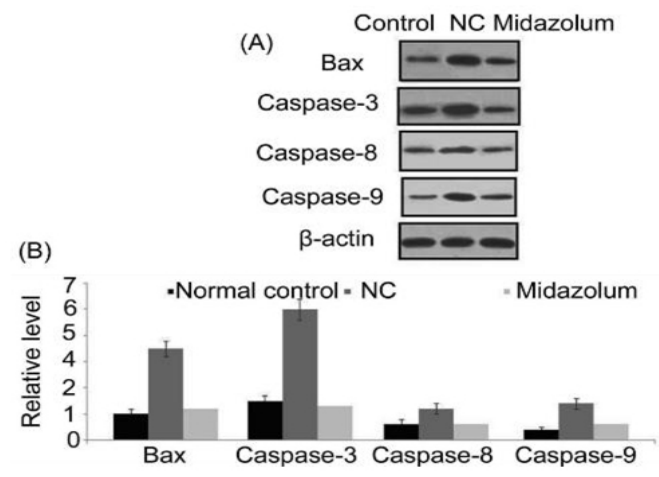

Figure 7: Effect of midazolum on Bax and caspase-3, caspase-8 and caspase- 9 level in rat model of convulsion. The Bax and caspase- $3 / 8 / 9$ levels in the brain tissues were determined by western blot assay; ${ }^{*} p<0.05,{ }^{* *} p<0.02$ vs. the untreated convulsion rat group

\section{Midazolum inhibits autophagy in rats with convulsion}

In rats with convulsion the levels of LC3-2 and Beclin-1 were markedly increased compared to normal control group (Figure 8). Midazolum treatment of the rats with convulsion suppressed LC3-2 and Beclin-1 expression markedly when compared to untreated rats. The p62 expression in rats with convulsion was higher than those of rats in normal control group. The level of p62 was markedly reduced in rats with convulsion on treatment with midazolum.

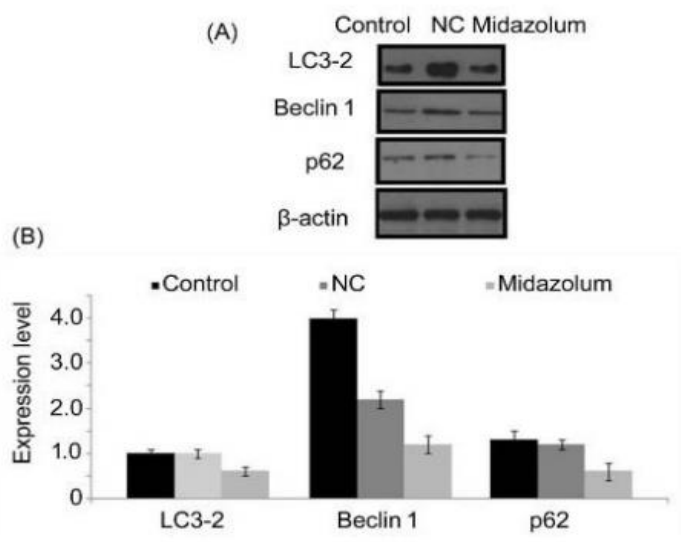

Figure 8: Effect of midazolum on autophagy related factors in brain tissues of convulsion rat. (A) The level of LC3-2, Beclin-1 and p62 in rat brain tissues with convulsion was determined using western blot assay. (B) The expression levels were quantified using $\beta$ actin as loading control; ${ }^{*} p<0.02$ and ${ }^{* *} p<0.01$ vs. untreated convulsion rat group

Trop J Pharm Res, March 2020; 19(3): 561 


\section{DISCUSSION}

Recurrent convulsion has been found to endanger the children's lives at various stages of development hindering their physical and intellectual growth [16]. Therefore, understanding the alterations in hippocampus may be beneficial for treatment of convulsion by inhibiting neurocyte cell apoptosis and promoting proliferation [17]. It was reported that administration of midazolam preserves neuronal dendritic structures and does not affect the development of neurons during anesthesia [8].

The present study investigated the effect of midazolam on convulsion in rat model in vivo and neurocyte cells in vitro. The data showed neurocyte proliferation increase significantly in vitro by midazolam treatment compared to convulsion model of neurocytes. In the rat model of convulsion large sized edema were observed and neurocyte cells showed apoptosis. Edema was absent and neurocyte cell growth normal in the rat model of convulsion on treatment with midazolam. Autophagy is the cycling process for proteins characterized by the accumulation of double membrane encapsulated autophagosomes [18]. The process of autophagy is regulated by the lysosome degradation pathway [5]. Autophagy significantly contributes to death and cell differentiation, immunity and aging [17].

The pathogenesis of various malignant tumors and neurological diseases is associated with the autophagy [18]. It is the mechanism of selfadoption operating via removal of damaged cell organelles and mis-folded proteins, and restoration of tissue homeostasis by providing nutrients [18]. Impairment as well as excessive activation of autophagy leads to various diseases including neurological disorders [19]. The neurological damage due to autophagy is indicated by higher expression of autophagy marker protein, LC3 in the brain tissues [19]. The present study showed lower expression of LC3 in convulsion model of neurocytes when compared to normal neurocytes.

LC3 and Beclin-1 expressions were markedly promoted in the convulsion model of neurocytes in vitro on exposure to midazolam. The expression of LC3 and Beclin-1 were also increased in vivo in the rat model of convulsion on treatment with midazolam. These findings provided evidence that midazolam increased proliferation of neurocytes both in vitro and in vivo in rat model of convulsion via up-regulation of LC3 and Beclin-1 expression. The expression of Bax protein which is regulated by apoptotic genes has been reported to increase the apoptosis of cells $[20,21]$.

Caspases are the proteolytic enzymes which induce apoptosis by cleaving various proteins like PARP [22,23]. The PARP is involved in maintaining DNA integrity and repairing the DNA damage $[22,23]$. In the present study caspase$3 / 8 / 9$ and Bax expression was markedly higher in convulsion model of neurocyte cells compared to the normal neurocyte cells. The midazolam exposure of convulsion model of neurocyte cells suppressed the expression of caspase-3, caspase-8 and caspase-9and Bax markedly when compared to untreated neurocytes. To ascertain that midazolam promotes neurocyte cell proliferation in vitro and in vivo via activation of autophagy neurocyte cells were exposed to autophagy inhibitor, 3-MA. The data showed that 3-MA alleviated effect of midazolam on proliferation, caspase-3, caspase- 8 and caspase9 and Bax.

\section{CONCLUSION}

The study revealed for the first time that midazolam promotes neurocyte cell proliferation in vitro and in vivo in a rat model. Moreover, midazolam suppresses Bax and caspase-3, caspase-8 and caspase-9 expression in neurocyte cells and therefore may be useful for the treatment of convulsion. However, further studies, including clinical investigations to ascertain.

\section{DECLARATIONS}

\section{Conflict of interest}

No conflict of interest is associated with this work.

\section{Contribution of authors}

We declare that this work was done by the authors named in this article and all liabilities pertaining to claims relating to the content of this article will be borne by the authors. Juan Shi and Shuzhong Jiang drafted this manuscript. Qinhua Wang, Jiajia Hua, Feifan Xu, Delin Gu collected materials and offered assistance in revision of this manuscript. Hui Zhou designed the whole study.

\section{Open Access}

This is an Open Access article that uses a funding model which does not charge readers or their institutions for access and distributed under the 
terms of the Creative Commons Attribution License (http://creativecommons.org/licenses/by/ 4.0) and the Budapest Open Access Initiative (http://www.budapestopenaccessinitiative.org/rea d), which permit unrestricted use, distribution, and reproduction in any medium, provided the original work is properly credited.

\section{REFERENCES}

1. Shinnar S, Pellock JM, Moshé SL, Maytal J, O'Dell C, Driscoll SM, Alemany M, Newstein D, DeLorenzo RJ. In whom does status epilepticus occur: Age-related differences in children. Epilepsia 1997; 38: 907-914.

2. Huang $L$, Cilio MR, Silveira $D C, M c C a b e B K$, Sogawa $Y$, Stafstrom CE, Holmes GL. Long-term effects of neonatal seizures: A behavioral, electrophysiological, and histological study. Brain Res Dev Brain Res 1999; 118: 99-107.

3. Chin RF, Neville BG, Peckham C, Wade A, Bedford $H$, Scott RC. Treatment of community-onset, childhood convulsive status epilepticus: A prospective, populationbased study. Lancet Neurol 2008; 7: 696-703.

4. Roy H, Lippé S, Lussier F, Sauerwein HC, Lortie A, Lacroix J, Lassonde M. Developmental outcome after a single episode of status epilepticus. Epilepsy Behav 2011; 21: 430-436.

5. Zeng $X J$, Li P, Ning YL, Zhao $Y$, Peng $Y$, Yang $N$, Zhao $Z A$, Chen JF, Zhou YG. Impaired autophagic flux is associated with the severity of trauma and the role of $A 2 A R$ in brain cells after traumatic brain injury. Cell Death Dis 2018; 9: 252.

6. Sun $L$, Zhao $M$, Wang $Y$, Liu A, LV M, Li Y, Yang $X, W u$ $Z$. Neuroprotective effects of miR-27a against traumatic brain injury via suppressing FoxO3a-mediated neuronal autophagy. Biochem Biophys Res Commun 2017; 482: 1141-1147.

7. Chen X, Wang H, Zhou M, Li X, Fang Z, Gao H, Li Y, Hu $W$. Valproic acid attenuates traumatic brain injury-induced inflammation in vivo: Involvement of autophagy and the Nrf2/ARE signaling pathway. Front Mol Neurosci 2018; 11: 117.

8. Vutskits L, Gascon E, Tassonyi E, Kiss JZ. Clinically relevant concentrations of propofol but not midazolam alter in vitro dendritic development of isolated gammaaminobutyric acid-positive interneurons. Anesthesiology 2005; 102: 970-976.

9. Jevtovic-Todorovic $V$, Hartman RE, Izumi $Y$, Benshoff ND, Dikranian K, Zorumski CF, Olney JW, Wozniak DF. Early exposure to common anesthetic agents causes widespread neurodegeneration in the developing rat brain and persistent learning deficits. J Neurosci 2003; 23: 876-882.

10. Mishra SK, Kang JH, Lee CW, Oh SH, Ryu JS, Bae YS, Kim HM. Midazolam induces cellular apoptosis in human cancer cells and inhibits tumor growth in xenograft mice. Mol Cells 2013; 36: 219-226.

11. Young C, Jevtovic-Todorovic V, Qin YQ, Tenkova $T$, Wang $\mathrm{H}$, Labruyere J, Olney JW. Potential of ketamine and midazolam, individually or in combination, to induce apoptotic neurodegeneration in the infant mouse brain. Br J Pharmacol 2005; 146: 189-197.

12. Stevens MF, Werdehausen $R$, Gaza N, Hermanns $H$, Kremer D, Bauer I, Küry $P$, Hollmann MW, Braun S. Midazolam activates the intrinsic pathway of apoptosis independent of benzodiazepine and death receptor signaling. Reg Anesth Pain Med 2011; 36: 343-349.

13. Casellas $P$, Galiegue S, Basile AS. Peripheral benzodiazepine receptors and mitochondrial function. Neurochem Int 2002; 40: 475-486.

14. National Research Council (US) Committee for the Update of the Guide for the Care and Use of Laboratory Animals: Guide for the care and use of laboratory animals. 8th edition. National Academies Press, Washington, DC, 2011.

15. Lively S, Brown IR. Analysis of the extracellular matrix protein SC1 during reactive gliosis in the rat lithiumpilocarpine seizure model. Brain Res 2007; 1163: 1-9.

16. So EC, Chang YT, Hsing CH, Poon PW, Leu SF, Huang $B M$. The effect of midazolam on mouse Leydig cell steroidogenesis and apoptosis. Toxicol Lett 2010; 192: 169-178.

17. Renaud MI, Lambregts SA, de Kloet AJ, CatsmanBerrevoets CE, van de Port IG, Van Heugten CM. Activities and participation of children and adolescents after mild traumatic brain injury and the effectiveness of an early intervention (Brains Ahead!): Study protocol for a cohort study with a nested randomised controlled trial. Trials 2016; 17: 236.

18. Cui C, Cui J, Jin F, Cui Y, Li R, Jiang X, Tian Y, Wang K, Jiang $P$, Gao J. Induction of the Vitamin $D$ receptor attenuates autophagy dysfunction-mediated cell death following traumatic brain injury. Cell Physiol Biochem 2017; 42: 1888-1896.

19. Wolf MS, Bayir H, Kochanek PM, Clark RSB. The role of autophagy in acute brain injury: A state of flux? Neurobiol Dis 2019; 122: 9-15.

20. Deyhimi P, Tavakoli P. Study of apoptosis in oral pemphigus vulgaris using immunohistochemical marker Bax and TUNEL technique. J Oral Pathol Med 2013; 42: 409-414.

21. Banadyga L, Veugelers $K$, Campbell S, Barry $M$. The fowlpox virus BCL-2 homologue, FPV039, interacts with activated Bax and a discrete subset of BH3-only proteins to inhibit apoptosis. J Virol 2009; 83: 7085-7098.

22. Riedl SJ, Shi Y. Molecular mechanisms of caspase regulation during apoptosis. Nat Rev Mol Cell Biol 2004; 5: 897-907.

23. Krishnakumar $R$, Kraus WL. The PARP side of the nucleus: molecular actions, physiological outcomes, and clinical targets. Mol Cell 2010; 39: 8-24. 